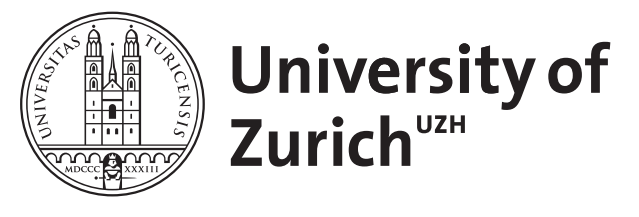

\title{
Inefficient policies and incumbency advantage
}

Hodler, R ; Loertscher, S ; Rohner, D

\begin{abstract}
We present a model of (re)elections in which an incumbency advantage arises because the incumbent can manipulate issue salience by choosing inefficient policies in the policy dimension in which he is the stronger candidate. The voters are uncertain about the state of the world and the incumbent's choice of policy. Under complete information they would reelect the incumbent if and only if the state is sufficiently high. Undesirable policy outcomes may be due to either a bad state or the incumbent's choice of inefficient policies. The incumbent uses inefficient policies in intermediate states, whereby he creates uncertainty about the true state in such a way that voters are better off in expectation reelecting him. Hence the equilibrium exhibits an incumbency advantage that stems from asymmetric information and the use of inefficient policies.
\end{abstract}

DOI: https://doi.org/10.1016/j.jpubeco.2010.05.002

Posted at the Zurich Open Repository and Archive, University of Zurich

ZORA URL: https://doi.org/10.5167/uzh-42449

Journal Article

Accepted Version

Originally published at:

Hodler, R; Loertscher, S; Rohner, D (2010). Inefficient policies and incumbency advantage. Journal of Public Economics, 94(9-10):761-767.

DOI: https://doi.org/10.1016/j.jpubeco.2010.05.002 


\title{
Inefficient Policies and Incumbency Advantage*
}

\author{
Roland Hodler†, Simon Loertscher ${ }^{\ddagger}$ and Dominic Rohner ${ }^{\S}$
}

April 13, 2010

\begin{abstract}
We present a model of (re)elections in which an incumbency advantage arises because the incumbent can manipulate issue salience by choosing inefficient policies in the policy dimension in which he is the stronger candidate. The voters are uncertain about the state of the world and the incumbent's choice of policy. Under complete information they would reelect the incumbent if and only if the state is sufficiently high. Undesirable policy outcomes may be due to either a bad state or the incumbent's choice of inefficient policies. The incumbent uses inefficient policies in intermediate states, whereby he creates uncertainty about the true state in such a way that voters are better off in expectation reelecting him. Hence the equilibrium exhibits an incumbency advantage that stems from asymmetric information and the use of inefficient policies.
\end{abstract}

JEL code: D72, C72

Keywords: Elections, Incumbency Advantage, Political Economics

\footnotetext{
${ }^{*}$ We are grateful to two anonymous referees for comments and suggestions that have improved the paper considerably. We would also like to thank seminar participants at the Universities of Munich, Tilburg, Zurich, the WZB Berlin, participants at the Public Choice conference 2007 in Amsterdam and the Econometric Society Australasian Meeting 2007 in Brisbane, many of our colleagues and Rosemary Humberstone and Fabrizio Zilibotti for helpful comments and discussions. Dominic Rohner gratefully acknowledges financial support from the Swiss National Science Foundation (SNF grant no. 100014-122636).

${ }^{\dagger}$ Study Center Gerzensee; and Department of Economics, University of Melbourne. Email: roland.hodler@szgerzensee.ch

${ }^{\ddagger}$ Department of Economics, University of Melbourne. Email: simonl@unimelb.edu.au.

${ }^{\S}$ Department of Economics, University of Zurich. Email: drohner@iew.uzh.ch.
} 


\section{Introduction}

How political leaders should be chosen and whether they can be trusted to act in the public's best interest is a question of natural concern and relevance. Elections are a widely used mechanism to allow people to select the political leaders they perceive as best suited to govern. However, the very fact that the incumbent head of government is reelected if he is perceived as better suited to govern than his challenger may induce him to choose socially costly policies if this allows him to shape the voters' perception in a favorable way. We provide a model in which in equilibrium elections lead to an incumbency advantage that stems from inefficient policies in a policy dimension in which the incumbent is known to be stronger than his challenger. To the best of our knowledge, the mechanism that generates an incumbency advantage in our model is novel, and so are its empirical predictions.

The main ingredients of the model are the following: The incumbent knows the state of the world, say the threat from criminals, whereas the voters do not. The preferences of the voters are such that under complete information they would elect the candidate who is known to be better at fighting crime, but potentially worse in other dimensions, if and only if the threat from criminals is above a certain threshold level. The incumbent can choose to fight crime efficiently or not. The voters do not observe this policy choice, but they do observe the resulting policy outcome, say the crime rate. The incumbent dislikes high crime rates like the voters do, but he also has a preference for staying in office. Therefore, he may be willing to trade off higher crime rates for improvements in his reelection chances.

In equilibrium the incumbent always chooses efficient policies if he is known to be weaker in fighting crime than his challenger because his strategic incentives are well aligned with the common interest in efficient policies and low crime rates. The more interesting situation arises if the incumbent is stronger than the challenger in fighting crime. In equilibrium such an incumbent also employs efficient policies both in high states in which crime is a very serious issue and in low states in which crime is only a minor problem. Observing the resulting crime rate, the voters correctly infer whether the state is above or below the threshold level, and they reelect the incumbent in the high states, but not in the low states. However, unless the incumbent's preference for staying in office is weak, the incumbent chooses inefficient policies in intermediate states. Observing intermediate levels of the crime rate, the voters can therefore not tell whether this crime rate is the result of the use of inefficient policies when the threat from criminals is moderately low or of the use of efficient policies when this threat is moderately 
high. However, in these instances the voters' beliefs have been targeted by the incumbent in such a way that their expected utility of reelecting him exceeds their expected utility of electing the challenger. In equilibrium the incumbent is therefore reelected whenever he uses inefficient policies, and he is (re)elected more often than he would be if his challenger had been in office, or if the voters were fully informed. Hence the incumbent enjoys an incumbency advantage that is due to inefficient policies and asymmetric information.

One of the two main predictions of our model is the presence of an incumbency advantage. There is a substantial empirical literature finding a sizable and robust electoral advantage of incumbents over challengers (e.g. Ansolabehere and Snyder, 2002; Ansolabehere et al., 2006). The other main prediction is that prior to elections office-motivated incumbents should sometimes implement policies inefficiently. In particular, they should do so in policy dimensions in which they are perceived to be strong and in ways that may not be observed by most voters. ${ }^{1}$ Our discussion focuses on examples in the fields of national security, where right-wing parties are perceived to be strong, and poverty and unemployment, where left-wing parties are considered to be strong (e.g. Petrocik, 1996).

In their study on terrorism and electoral outcomes in Israel, Berrebi and Klor (2006) provide evidence that the support for right-wing parties increases in the number of terror attacks, and show that right-wing incumbents impose total or partial closures on Westbank or Gaza much less frequently before elections than left-wing incumbents. These findings are consistent with the notion that prior to elections right-wing incumbents take less precautions against terror attacks than left-wing incumbents even though they have the reputation of being tougher. Similarly, nationalist parties tend to benefit politically from communal or ethnic riots involving minorities. Wilkinson $(2004,2009)$ shows that Indian right-wing parties had electoral gains from riots between Hindus and Muslims and that in areas controlled by right-wing parties such as the Hindu nationalist BJP before elections police action to stop riots was inefficient. Wilkinson finds that controlling a riot does not only depend on the police budget, but also largely on "whether the police will be deployed quickly, and with sufficient will or force" and whether it is "given sufficient direction by their political masters" (Wilkinson, 2009: 336). He argues that similar inefficient anti-riot policies by nationalist parties took place in Ireland, Malaysia and Romania.

\footnotetext{
${ }^{1}$ It is not necessary that the state of the world and the inefficiency are unobservable with certainty or at any cost, but that with some positive probability they are unobserved by most voters. This is consistent with the empirical evidence that voters are generally rather ill-informed about facts relevant to politics (see e.g. Bartels, 1996, or Blendon et al., 1997).
} 
According to our model, left-wing politicians known to be strong at fighting poverty and unemployment may sometimes choose inefficient policies to improve their electoral prospects. Examples include the "populist" macroeconomic policies implemented by various Latin American governments in recent decades. According to Dornbusch and Edwards (1990: 247) allegedly redistributive "populist policies do ultimately fail; and when they fail it is always at a frightening cost to the very groups who were supposed to be favored." Our paper suggests that rather than being based on "bad" economics such inefficient policies may have been based on "good" Machiavellian politics.

Our paper is related to the literature on issue ownership (Budge and Farlie, 1983; Petrocik, 1996), with which it shares the two main premises that a given party "owns" some issues for which it is perceived as strong, and that electoral support depends on what issues are considered salient before the election. Hence the parties have incentives to make the voters believe that "their" issues are particularly pressing. While the existing issue ownership literature is essentially empirical and focuses on campaigning by both candidates to affect issue salience (e.g. Petrocik et al., 2003), in our framework the incumbent has an informational advantage and can use inefficient policies to manipulate beliefs on issue salience. Hence, our model yields an incumbency advantage that cannot be explained by issue ownership in campaigning.

Our paper is also closely related to the contributions of Rogoff and Sibert (1988; see also Rogoff, 1990), Canes-Wrone et al. (2001), and Shi and Svensson (2006), who all study games between voters and an incumbent whose competence is unknown to voters. ${ }^{2}$ This incumbent can use inefficient policies to appear more competent than he is and, thereby, improve his reelection chances. In contrast to this existing work, the focus of our paper lies on situations in which voters would like to base their voting decision on the unknown state of the world, rather than the unknown type of the incumbent. This gives rise to a setting with partisan differences in which left- and right-wing incumbents face different incentives depending on the relevant policy dimension.

There are other substantial differences between our model and the one of Rogoff and Sibert (1988). They assume that the incumbent has private information about his competence, but

\footnotetext{
${ }^{2}$ See Besley (2007) for an excellent overview of models of reelections. Our paper is further related to Alesina and Cukierman (1990), Coate and Morris (1995), and Dellis (2009). Alesina and Cukierman present a model similar to Rogoff and Sibert in which the incumbent has private information about his policy preferences. Coate and Morris show that an incumbent may choose inefficient ways of redistribution to special interest groups to conceal his type. Dellis presents a model in which prior to election the incumbent may not address salient issues on which the voters like his stance.
} 
is imperfectly informed about the preferences of the median voter. For any level of expected competence, he has better reelection chances when choosing inefficient rather than efficient policies. His equilibrium strategy is thus fully separating and revealing. Hence in equilibrium he has no incumbency advantage. In our model, the incumbent knows the median voter's preferences. He thus has no incentive to choose inefficient policies in low or high states, i.e. when he cannot affect the election outcome. As a result, his equilibrium strategy is partially pooling and he enjoys an incumbency advantage. ${ }^{3}$

Canes-Wrone et al. (2001) study leadership and pandering by incumbents in a model with binary states, binary incumbent types and binary policies. In equilibrium an incompetent incumbent may use inefficient policies when elections are relatively close, and only when the equilibrium is in mixed strategies. As a consequence, there is no clear incumbency advantage, and the incumbent is sometimes not reelected even when the voters would be better off reelecting him, which cannot happen in our model.

In line with the career concerns model of Holmström (1999), Shi and Svensson (2006) assume that the incumbent faces the same uncertainty about his competence when choosing his policy as the voters do when casting their votes. In equilibrium the incumbent chooses an inefficient policy but cannot improve his reelection prospects as the voters expect him to do so. If the incumbent knew as little as the voters about the true state of the world, our model would yield a similar result: The incumbent might choose an inefficient policy, but the voters would anticipate his policy choice and could correctly infer the true state. The incumbent's informational advantage is therefore necessary for the incumbency advantage to arise in our model, but not for inefficient equilibrium policies.

The remainder of the paper is organized as follows: Section 2 lays out the model. Section 3 characterizes the equilibrium. Section 4 discusses our results, and Section 5 concludes. The appendix contains longer proofs.

\section{The Model}

There are two candidates, $A$ and $B$, and two periods $t=1,2$. This is the simplest structure that allows for reelection and hence the possibility of incumbency advantage. For now we assume

\footnotetext{
${ }^{3}$ Two technical comments are in order: First, there also exist pooling equilibria in Rogoff and Sibert's model, but Rogoff and Sibert discard them on the ground that they do not satisfy the Cho-Kreps intuitive criterion. The partially pooling equilibrium of our model satisfies the Cho-Kreps intuitive criterion. Second, the equilibrium in our model is robust to the introduction of uncertainty with respect to the median voter's preferences, provided this uncertainty is small.
} 
that one of these candidates is in office for exogenous reasons in period one. The candidate in office is called the incumbent, the other candidate is called the challenger. At the end of period one, the (median) voter $M$ either reelects the incumbent or replaces him by the challenger. Throughout the paper we refer to an incumbent as "he" and to the voter as "she". Since there are two types of incumbents, $A$ and $B$, there are two versions of this game differing in the incumbent's type. In each version, there are three players: the incumbent, the challenger, and the voter.

Information: Information is asymmetric in that in each period the state of the world $z$ is known to the candidates, but not to the voter. For simplicity, the state is assumed to be time invariant. We assume that $z \in \mathbb{R}$ is a random draw from the commonly known distribution $F(z)$ whose density $f(z)$ is continuous and strictly positive for all $z$. The voter's prior belief $\mu(z)$ that state $z$ has been realized therefore satisfies $\mu(z)=f(z)$. The voter observes the policy outcome $y_{t}$ in period $t$, which depends both on $z$ and the action undertaken by the incumbent. One can think of $z$ as the severity of an international economic crisis and $y_{t}$ as the national unemployment rate. Alternatively, one can think of $z$ as the number of potential delinquents and $y_{t}$ as the number of crimes committed.

Timing and Actions: Having learned the state $z$ at the beginning of period one, the incumbent chooses between low and high quality policies $q_{1} \in\{\underline{q}, \bar{q}\}$, with $\underline{q}<\bar{q}$. This choice does not involve any direct cost. The quality $q_{1}$ can be thought of as measuring the efficiency with which the incumbent tackles unemployment, or alternatively as the efficiency with which police are employed to fight crime. At the end of period one, but prior to election day, the voter observes the policy outcome $y_{1}$, but not the incumbent's choice of $q_{1}$. She then updates her beliefs about the true state and either reelects the incumbent or elects the challenger. In period two, the policy outcome $y_{2}$ is realized after the (re)elected candidate's choice of $q_{2} \in\{\underline{q}, \bar{q}\}$, and then the game ends.

Technology: In each period, the policy outcome $y_{t}$ depends on the state $z$, the quality $q_{t}$ and the candidate in office $i \in\{A, B\}$ as follows:

$$
y_{t}=y\left(q_{t}, z, i\right),
$$


where $y($.$) satisfies 0<y\left(q_{t}, z, A\right)<y\left(q_{t}, z, B\right)$ for any $q_{t}$ and $z$, and $y(\bar{q}, z, i)<y(\underline{q}, z, i)$ for any $z$ and $i$. Hence, the policy outcome is lower when $A$ is in office and when high quality policies are chosen. Moreover, we assume that $y\left(q_{t}, z, i\right)$ is continuous and increasing in $z$ and satisfies $0<\partial y\left(q_{t}, z, A\right) / \partial z<\partial y\left(q_{t}, z, B\right) / \partial z$ for any $q_{t}$ and $z$. This latter assumption implies that an increase in state $z$ has a stronger effect on the policy outcome $y_{t}$ if $B$ is in office than if $A$ is in office.

Payoffs: The voter prefers a low policy outcome $y_{t}$ to a high one, and she gets some exogenous benefit $\theta_{i}$ from having candidate $i \in\{A, B\}$ in office. Her instantaneous von NeumannMorgenstern utility with candidate $i$ in office and policy outcome $y_{t}$ is

$$
\omega_{t}=\theta_{i}-c\left(y_{t}\right)
$$

where $c\left(y_{t}\right)$ is continuous and satisfies $c^{\prime}\left(y_{t}\right)>0$ and $c^{\prime \prime}\left(y_{t}\right) \geq 0$. Hence, high crime or unemployment rates decrease utility. We assume $\theta_{A}<\theta_{B}$. While candidate $A$ is better at fighting the undesired policy outcome, the voter thus benefits from having candidate $B$ in office for some other reason, e.g., because $B$ is better in some policy dimension in which there is no quality choice. ${ }^{4}$ As a tie-breaking rule, we further assume that the voter elects $A$ if she is indifferent between the two candidates. Using (1) and (2), we can write the voter's indirect utility in state $z$ with quality $q_{t}$ and candidate $i$ in office as

$$
u\left(q_{t}, z, i\right)=\theta_{i}-c\left(y\left(q_{t}, z, i\right)\right) .
$$

Observe that $u(\bar{q}, z, i)>u(\underline{q}, z, i)$ for all $z$ and both $i$ because $y(\bar{q}, z, i)<y(\underline{q}, z, i)$ and $c^{\prime}\left(y_{t}\right)>0$.

Candidates are office- as well as policy-motivated. The instantaneous utility of each candidate $j \in\{A, B\}$ is $\Psi+u\left(q_{t}, z, i\right)$ if in office (i.e. if $\left.j=i\right)$, and $u\left(q_{t}, z, i\right)$ otherwise, where $\Psi \geq 0$ measures their office rent. For simplicity, we assume that utility is additively separable over time and we abstract from discounting.

Solution Concept: The solution concept we employ is Perfect Bayesian Equilibrium (PBE). We restrict our attention to PBE in pure strategies, and we add the following restriction on the voter's off equilibrium beliefs: When observing a policy outcome $y_{1}$ that cannot result from the

\footnotetext{
${ }^{4}$ In a web appendix, we present an extended version of our model with two policy dimensions in which there is a quality choice. We assume that each candidate is stronger than his challenger in one of the two dimensions. We find that any incumbent can use his informational advantage and low quality policies in the policy dimension in which he is stronger to sometimes manipulate the voter into reelecting him when doing so is not in her interest.
} 
incumbent having played his equilibrium strategy, the voter has "Laplacian" beliefs, i.e., she assumes that the incumbent may have played the "wrong" $q_{1}$ with the same error probability at each state $z$ consistent with $y_{1}$. This implies that the voter's off equilibrium beliefs over the states consistent with the observed outcome $y_{1}$ must be proportional to her prior beliefs over these states. ${ }^{5}$

\section{The Equilibrium}

The quality $q_{2}$ that the office holder chooses in period two is straightforward to determine: Since there are no strategic incentives, and since $u(\bar{q}, z, i)>u(\underline{q}, z, i)$ for any $z$ and $i$, the office holder $i \in\{A, B\}$ chooses high quality $\bar{q}$ for all $z$ in period two.

Having solved the period two subgame, we focus on period one in the remainder of this section. We start by deriving who the voter would elect under full information, i.e., if she knew the true state $z$. The difference between her utility in period two when $A$ is in office and when $B$ is in office is

$$
\Delta u(z) \equiv u(\bar{q}, z, A)-u(\bar{q}, z, B)
$$

This difference $\Delta u(z)$ increases in $z$ because the benefit of having $A$ in office, who is better at reducing the undesired policy outcome $y_{2}$, increases in $z$, while the benefit of having $\mathrm{B}$ in office, $\theta_{B}-\theta_{A}$, is independent of $z$. The threshold value $\tilde{z}$ that makes the voter indifferent between $A$ and $B$ is implicitly defined by $\Delta u(\tilde{z})=0$. It follows:

Lemma 1 Under full information the voter would elect $A$ if $z \geq \tilde{z}$, and $B$ otherwise.

However, the voter does not know the true state $z$ and can only base her decision on the observed policy outcome $y_{1}$ and her updated beliefs $\mu\left(z \mid y_{1}\right)$. We discuss next how the Bayesian updating and the optimal behavior of the voter depend on $y_{1}$ and the incumbent's strategy. We then derive the optimal policy choice of the two types of incumbents $i \in\{A, B\}$.

Given an incumbent of type $i$, any observed policy outcome $y_{1}$ is in principle consistent with two different states $z$. Denote by $\underline{z}\left(y_{1}\right)$ the state consistent with quality $\underline{q}$ and observation $y_{1}$, and by $\bar{z}\left(y_{1}\right)$ the state consistent with $\bar{q}$ and $y_{1}$. That is, given $i, \underline{z}\left(y_{1}\right)$ and $\bar{z}\left(y_{1}\right)$ are defined

\footnotetext{
${ }^{5}$ Laplacian off equilibrium beliefs can be justified on both technical and intuitive grounds: It can be shown that in our setup imposing Laplacian off equilibrium beliefs is equivalent to imposing the Perfect Sequential Equilibrium refinement of Grossman and Perry (1986). Moreover, such prior preserving beliefs seem a plausible assumption, as whenever off equilibrium observations are possible the incumbent can in principle gain from an off-the-equilibrium path deviation at any state consistent with this observation.
} 
by

$$
y_{1}=y\left(\underline{q}, \underline{z}\left(y_{1}\right), i\right) \quad \text { and } \quad y_{1}=y\left(\bar{q}, \bar{z}\left(y_{1}\right), i\right) .
$$

Our assumptions on $y\left(q_{t}, z, i\right)$ imply that $\underline{z}\left(y_{1}\right)<\bar{z}\left(y_{1}\right)$, and that both $\underline{z}\left(y_{1}\right)$ and $\bar{z}\left(y_{1}\right)$ are continuous and increasing in $y_{1}$. The property that no state other than $\underline{z}\left(y_{1}\right)$ and $\bar{z}\left(y_{1}\right)$ is a priori consistent with an observed $y_{1}$ restricts the voter's beliefs $\mu\left(z \mid y_{1}\right)$ substantially because it implies $\mu\left(\underline{z}\left(y_{1}\right) \mid y_{1}\right)+\mu\left(\bar{z}\left(y_{1}\right) \mid y_{1}\right)=1$.

Given an observed policy outcome $y_{1}$, the voter elects $A$ if

$$
\mu\left(\underline{z}\left(y_{1}\right) \mid y_{1}\right) \Delta u\left(\underline{z}\left(y_{1}\right)\right)+\mu\left(\bar{z}\left(y_{1}\right) \mid y_{1}\right) \Delta u\left(\bar{z}\left(y_{1}\right)\right) \geq 0,
$$

and $B$ otherwise. Her decision problem is straightforward when only one state $z$ is consistent with the observed $y_{1}$ given the incumbent's strategy. This is the case when the incumbent plays high quality $\bar{q}$ in both of the technically possible states $\underline{z}\left(y_{1}\right)$ and $\bar{z}\left(y_{1}\right)$. Then, the voter's belief is $\mu\left(\bar{z}\left(y_{1}\right) \mid y_{1}\right)=1$ and she elects $A$ if and only if $y_{1} \geq y^{L}$, where $y^{L}$ is the unique outcome that satisfies $\Delta u\left(\bar{z}\left(y^{L}\right)\right)=0$. Similarly, when the incumbent plays low quality $\underline{q}$ in both $\underline{z}\left(y_{1}\right)$ and $\bar{z}\left(y_{1}\right)$, the voter's belief is $\mu\left(\underline{z}\left(y_{1}\right) \mid y_{1}\right)=1$ and she elects $A$ if and only if $y_{1} \geq y^{H}$, where $y^{H}$ is such that $\Delta u\left(\underline{z}\left(y^{H}\right)\right)=0 .^{6}$

However, the voter cannot infer the true state $z$ after observing the policy outcome $y_{1}$ if the incumbent plays $\underline{q}$ at $\underline{z}\left(y_{1}\right)$ and $\bar{q}$ at $\bar{z}\left(y_{1}\right)$. Bayesian updating implies that she elects $A$ if and only if

$$
f\left(\underline{z}\left(y_{1}\right)\right) \Delta u\left(\underline{z}\left(y_{1}\right)\right)+f\left(\bar{z}\left(y_{1}\right)\right) \Delta u\left(\bar{z}\left(y_{1}\right)\right) \geq 0 .
$$

Now, for any $y_{1} \leq y^{L}$ she elects $B$ because $\Delta u\left(\underline{z}\left(y_{1}\right)\right)<\Delta u\left(\bar{z}\left(y_{1}\right)\right) \leq 0$. Similarly, for any $y_{1} \geq y^{H}$ she elects $A$ because $0 \leq \Delta u\left(\underline{z}\left(y_{1}\right)\right)<\Delta u\left(\bar{z}\left(y_{1}\right)\right)$. For $y_{1} \in\left(y^{L}, y^{H}\right)$ her decision problem is more involved since she would be better off with $B$ in state $\underline{z}\left(y_{1}\right)$ and with $A$ in state $\bar{z}\left(y_{1}\right)$. We know that the left-hand side of $(7)$ is continuous for all $y_{1}$, strictly negative for $y_{1}=y^{L}$ and strictly positive for $y_{1}=y^{H}$. Thus, there exists some $y^{\prime} \in\left(y^{L}, y^{H}\right)$ such that $(7)$ holds with equality. In general there may exist multiple thresholds satisfying this condition, but for simplicity we assume from here onwards that $y^{\prime}$ is unique. ${ }^{7}$ When observing $y_{1}$ and assuming that the incumbent plays $\underline{q}$ at $\underline{z}\left(y_{1}\right)$ and $\bar{q}$ at $\bar{z}\left(y_{1}\right)$, the voter thus elects $A$ if and only if $y_{1} \geq y^{\prime}$. It is useful to define $\underline{z}^{\prime} \equiv \underline{z}\left(y^{\prime}\right)$ and $\bar{z}^{\prime} \equiv \bar{z}\left(y^{\prime}\right)$. Observe that $\underline{z}^{\prime}<\tilde{z}<\bar{z}^{\prime}$.

\footnotetext{
${ }^{6}$ Equivalently $y^{L}$ and $y^{H}$ can be defined as the outcomes that satisfy $\bar{z}\left(y^{L}\right)=\tilde{z}=\underline{z}\left(y^{H}\right)$.

${ }^{7} \mathrm{~A}$ sufficient condition for $y^{\prime}$ to be unique (that is far from being tight) is that $f(z)$ is constant in the interval $\left[\underline{z}\left(y^{L}\right), \bar{z}\left(y^{H}\right)\right]$. None of our main results is qualitatively affected if $y^{\prime}$ is not unique.
} 
The intuition for the voter's behavior, taking the incumbent's strategy as given, is the following: Whenever $y_{1}$ is close to $y^{H}$, she knows that the true state is either close to $\tilde{z}$, in which case she will be somewhat better off with $B$, or close to $\bar{z}\left(y^{H}\right)$, in which case she will be much better off with $A$. She thus elects $A$. Conversely, she elects $B$ when $y_{1}$ is close to $y^{L}$ as she will either be much better off with $B$ or slightly better off with $A$.

Next, we focus on the equilibrium strategy of the two types of incumbents, $A$ and $B$. Any incumbent knows that the voter elects $B$ for any $y_{1}<y^{L}$ and $A$ for any $y_{1} \geq y^{H}$, independently of her beliefs $\mu\left(\bar{z}\left(y_{1}\right) \mid y_{1}\right)$. Consequently, when $z<z^{L} \equiv \underline{z}\left(y^{L}\right)$ or $z \geq z^{H} \equiv \bar{z}\left(y^{H}\right)$, any incumbent chooses high quality $\bar{q}$ because he cannot influence the election outcome.

With an incumbent of type $B$ it is easy to see that there exists an equilibrium in which he plays high quality $\bar{q}$ for all $z$ : If the voter expects $B$ to play $\bar{q}$ for all $z$, she correctly infers the state $z$ from the observed policy outcome $y_{1}$ and elects $B$ if and only if $y_{1}<y^{L}$. Given this strategy of the voter, $B$ has no incentive to deviate and to play low quality $\underline{q}$ because this would lead to a higher policy outcome $y_{1}$ without improving his reelection prospects. Indeed, playing $\underline{q}$ would make the voter think that the state $z$ is higher than it actually is, which would even $\operatorname{cost} B$ his reelection when $z \in\left[z^{L}, \tilde{z}\right)$. As shown in Appendix A, this equilibrium is unique. Summarizing, we therefore have: ${ }^{8}$

Proposition 1 The game with incumbent $B$ has a unique PBE in which $B$ plays $\bar{q}$ for all $z$ in period one, and the voter reelects $B$ for $y_{1}<y^{L}$ and elects $A$ otherwise.

This proposition implies that an incumbent who is weak in the relevant policy dimension would never choose low quality policies. The reason is that his strategic incentives are well aligned with the common interest in a low policy outcome. The voter can therefore always correctly infer the true state of the world. As under full information, she reelects $B$ if and only if $z<\tilde{z}$.

The equilibrium with incumbent $A$ may look differently because his strategic incentives conflict with the common interest in a low policy outcome. To see that a fully separating equilibrium may not exist, assume that the voter expects $A$ to play high quality $\bar{q}$ for all $z$. In this case $A$ is not reelected when playing $\bar{q}$ in states $z \in\left[z^{L}, \tilde{z}\right)$, but he would be reelected when playing $\underline{q}$ instead. Whether $A$ plays $\underline{q}$ in some states depends on his office rent $\Psi$. The immediate costs of low quality are $u(\bar{q}, z, A)-u(\underline{q}, z, A)$. The benefit from staying in office because of low quality is $\Psi+u(\bar{q}, z, A)-u(\bar{q}, z, B)$. Hence the benefit exceeds the costs

\footnotetext{
${ }^{8}$ Observe that our restriction on off equilibrium beliefs plays no role in Proposition 1 and Proposition 2 below.
} 


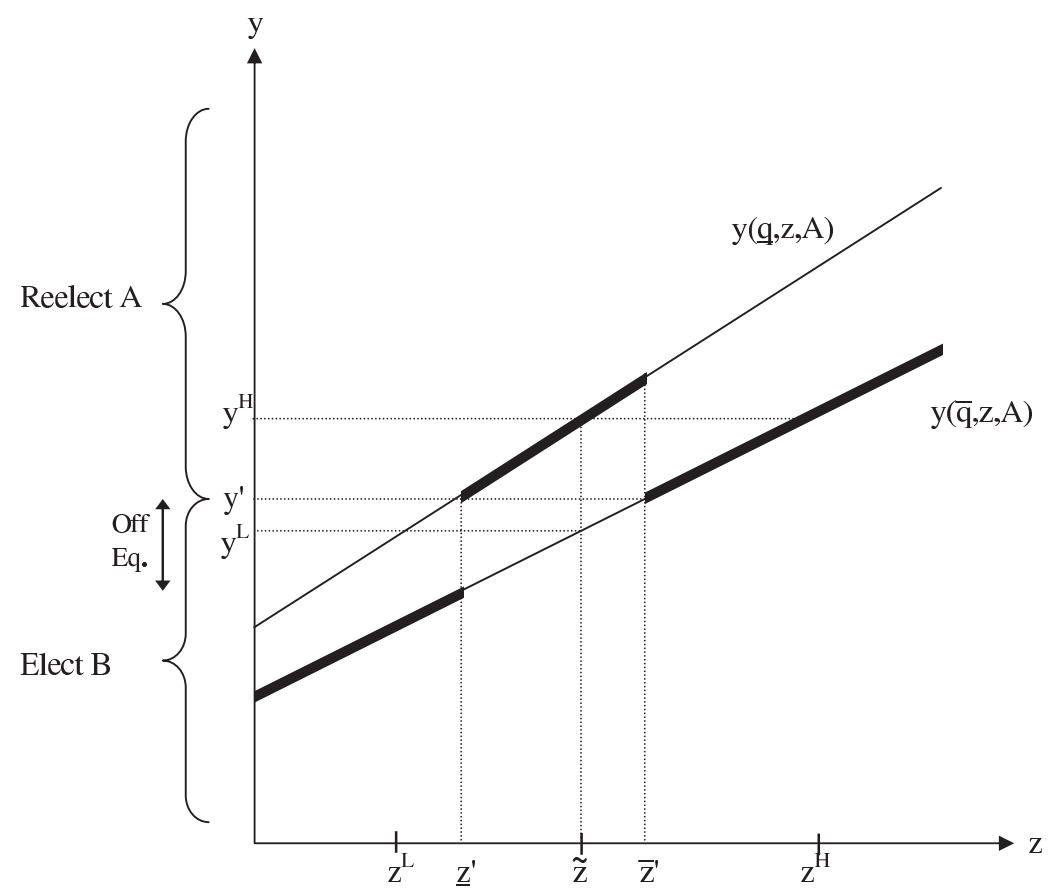

Figure 1: Equilibrium with incumbent $A$ and $\Psi>\bar{\Psi}$.

if and only if $\Psi>\hat{\Psi}(z) \equiv u(\bar{q}, z, B)-u(\underline{q}, z, A)$. The notation $\underline{\Psi} \equiv \min _{z \in\left[z^{L}, \bar{z}^{\prime}\right]} \hat{\Psi}(z)$ and $\bar{\Psi} \equiv \max _{z \in\left[z^{L}, \bar{z}^{\prime}\right]} \hat{\Psi}(z)$ is useful below.

An equilibrium in which incumbent $A$ plays high quality $\bar{q}$ for all $z$ exists only if $\Psi \leq \hat{\Psi}(z)$ for all $z \in\left[z^{L}, \tilde{z}\right)$. Then $A$ has no incentive to deviate if the voter expects him to play $\bar{q}$ for all $z$. As shown in Appendix A, this equilibrium is unique if $\Psi \leq \underline{\Psi}$. We therefore have the following result:

Proposition 2 For $\Psi \leq \underline{\Psi}$, the game with incumbent $A$ has a unique PBE in which A plays $\bar{q}$ for all $z$ in period one, and the voter reelects $A$ for $y_{1} \geq y^{L}$ and elects $B$ otherwise.

Hence, when always choosing high quality $\bar{q}$, incumbent $A$ is also reelected if and only if $z \geq \tilde{z}$.

However, there exists no equilibrium in which incumbent $A$ plays high quality $\bar{q}$ for all $z$ if his office rent $\Psi$ is relatively large, as he would want to deviate and play low quality $\underline{q}$ for $z \in\left[z^{L}, \tilde{z}\right)$. This leads us to our main result:

Proposition 3 For $\Psi>\bar{\Psi}$, the game with incumbent $A$ has a unique PBE with Laplacian off equilibrium beliefs, in which $A$ plays $q$ for $z \in\left[\underline{z}^{\prime}, \bar{z}^{\prime}\right)$ and $\bar{q}$ for any other $z$ in period one, and the voter reelects $A$ for $y_{1} \geq y^{\prime}$ and elects $B$ otherwise.

This proposition is illustrated in Figure 1. Incumbent $A$ 's strategy as a function of $z$ is highlighted with bold lines, and the voter's strategy is indicated on the vertical axis. It is easy to 
see that incumbent $A$ has no incentive to deviate given the equilibrium strategy of the voter and $\Psi>\bar{\Psi}$. He plays $\bar{q}$ if the election outcome is independent of his quality choice, but $q$ if doing so ensures his reelection whereas he would not be reelected when playing $\bar{q}$. By definition of $y^{\prime}$, the voter is better off in expectation electing $A$ for observations $y_{1} \in\left[y^{\prime}, y\left(q, \bar{z}^{\prime}, A\right)\right)$ even though she cannot infer the true state $z$. The observations $y_{1} \in\left[y\left(\bar{q}, \underline{z}^{\prime}, A\right), y^{\prime}\right)$ are off the equilibrium path, but our assumption of Laplacian off equilibrium beliefs implies that the voter would optimally elect $B$ for these observations. ${ }^{9}$

\section{Discussion}

In this section, we look at $A$ 's incumbency advantage and the welfare effects of elections, and we discuss why candidate $A$ could become the incumbent in the first place.

Incumbency Advantage: Proposition 3 shows that incumbent $A$ is reelected for all $z \geq \underline{z}^{\prime}$ if $\Psi>\bar{\Psi}$. Since $\underline{z}^{\prime}<\tilde{z}$, he is reelected in strictly more states than he would be under full information. From Proposition 1 we further know that as the challenger, $A$ is elected for any $z \geq \tilde{z}$. Hence, $A$ 's incumbency advantage, defined as the increase in his ex ante reelection probability due to incumbency, is $F(\tilde{z})-F\left(\underline{z}^{\prime}\right)>0 .{ }^{10}$ When observing $y_{1} \in\left[y^{\prime}, y^{H}\right)$ and reelecting $A$, the voter is of course aware that the true state is $\underline{z}\left(y_{1}\right)<\tilde{z}$ with probability $f\left(\underline{z}\left(y_{1}\right)\right) /\left(f\left(\bar{z}\left(y_{1}\right)\right)+f\left(\underline{z}\left(y_{1}\right)\right)\right)$, and that in this case she would be better off electing $B$. However, incumbent $A$ only induces the voter to remain uncertain if she is then in expectation better off reelecting him than electing $B$.

Welfare Effects of Elections: Two inefficiencies arise from the voter's perspective when $A$ is the incumbent and $\Psi>\bar{\Psi}$. First, she may end up with $A$ in office for another period while she would be better off with $B$. Her ex ante expected welfare loss due to this inefficiency is $W_{A} \equiv-\int_{\underline{z}^{\prime}}^{\tilde{z}} \Delta u(z) f(z) d z$, which is strictly positive since $\Delta u(z)<0$ for $z<\tilde{z}$, and increasing in

\footnotetext{
${ }^{9}$ The role of our restriction on off equilibrium beliefs is to pick a unique equilibrium. In the absence of this restriction, there exist multiple PBE if $\Psi>\hat{\Psi}(z)$ holds for some $z \in\left[\bar{z}^{\prime}, z^{H}\right]$ as well. However, all PBE share the same structure in that $A$ plays $q$ only for some intermediate $z$ and is always reelected when doing so. Note that all PBE satisfy the Cho-Kreps intuitive criterion, and all (but one) exhibit an incumbency advantage. Further note that if $\Psi \in(\underline{\Psi}, \bar{\Psi}], A$ may in equilibrium play $\underline{q}$ for some, but not all $z \in\left[\underline{z}^{\prime}, \bar{z}^{\prime}\right)$; and the voter may therefore again reelect him for some $z<\tilde{z}$.

${ }^{10}$ This definition of incumbency advantage is the same as the one advocated by Beviá and Llavador (2009). In our setup, the incumbency advantage coincides with the difference between $A$ 's reelection probability as incumbent with an informational advantage and his (hypothetical) reelection probability under full information.
} 
the likelihood of states in $\left[\underline{z}^{\prime}, \tilde{z}\right]{ }^{11}$ The second inefficiency from the voter's perspective is that she has to bear the costs of low quality policies in period one when $z \in\left[\underline{z}^{\prime}, \bar{z}^{\prime}\right)$. This inefficiency leads to an ex ante expected welfare loss of $W_{\underline{q}} \equiv \int_{\underline{z}^{\prime}}^{\bar{z}^{\prime}}[u(\bar{q}, z, A)-u(\underline{q}, z, A)] f(z) d z>0$. This expected welfare loss increases in the likelihood of states in $\left[\underline{z}^{\prime}, \bar{z}^{\prime}\right]$. It also tends to be the larger, the stronger the effect of the incumbent's policy choice $q_{1}$ on the policy outcome $y_{1}$.

Given these inefficiencies and assuming $\Psi>\bar{\Psi}$, the question arises whether the election at the end of period one is improving the voter's welfare at all compared to a situation in which the incumbent can stay in office for sure. In the simple case in which the incumbent is of type $B$, the voter's expected benefit from replacing incumbent $B$ when she is indeed better off with challenger $A$ in office equals $\int_{\tilde{z}}^{\infty} \Delta u(z) f(z) d z>0$. This benefit from the selection effect of elections is always positive and obviously larger when states $z \geq \tilde{z}$ are more likely. There is also a positive selection effect of elections when the incumbent is of type $A$. However, this effect is mitigated by the two inefficiencies just discussed. Elections are thus welfare improving if and only if

$$
-\int_{-\infty}^{\tilde{z}} \Delta u(z) f(z) d z-W_{A}-W_{\underline{q}} \geq 0 .
$$

This net benefit of elections is the larger, the lower the likelihood of states in $\left[\tilde{z}, \bar{z}^{\prime}\right)$ and the higher the likelihood of states below $\underline{z}^{\prime}$.

Endogenizing the Incumbent's Type: A related question is how candidate $A$ could have become the incumbent in the first place if $\Psi>\bar{\Psi}$, given that his behavior may result in various inefficiencies. So suppose that there is a pre-stage to our game, in which the voter can choose whether $A$ or $B$ becomes the incumbent in period one without having any insights about $z$ other than its distribution $F(z)$. Given $\Psi>\bar{\Psi}$, the voter prefers having $A$ as incumbent if and only if

$$
\int_{-\infty}^{\infty} \Delta u(z) f(z) d z-W_{A}-W_{\underline{q}} \geq 0
$$

The first term is the voter's expected benefit of having $A$ in office instead of $B$, under the hypothesis that both types of incumbents use efficient policies; and the other two terms are the inefficiencies associated with incumbent $A$. If the hypothetical benefit is negative, the voter obviously chooses $B$ as incumbent. Interestingly, however, if this benefit is positive and sufficiently large, the voter chooses $A$ as incumbent despite the inefficiencies $W_{A}$ and $W_{\underline{q}}$.

\footnotetext{
${ }^{11}$ To be precise, $W_{A}$ is higher with distribution $F_{1}(z)$ than with $F_{2}(z)$ if the corresponding densities satisfy $f_{1}(z)>f_{2}(z)$ for all $z \in\left[\underline{z}^{\prime}, \tilde{z}\right)$, assuming that $F_{1}(z)$ and $F_{2}(z)$ lead to the same $\underline{z}^{\prime}$ and $\bar{z}^{\prime}$. Subsequent statements about higher or lower likelihood of states $z$ in some interval are to be understood analogously.
} 


\section{Conclusions}

We have analyzed a model with strategic interactions between an incumbent office holder and voters who observe neither the state of the world nor whether the incumbent uses policy instruments efficiently or inefficiently. When the incumbent has a sufficiently strong desire to stay in office, he employs inefficient policies for some intermediate states in the policy dimension in which he is considered to be stronger than his challenger. Whenever the incumbent does so in equilibrium, the voters reelect him even though they would not reelect him for some of these states if they observed the state or the policy chosen, or if he were the challenger. Thus, the incumbent enjoys an incumbency advantage due to inefficient policies and asymmetric information. Since all types of incumbent employ efficient policies for non-intermediate states of the world, these states are revealed, which allows the voters to elect their preferred candidate. Therefore, in equilibrium elections have both a selection and an inefficiency inducing effect.

As right-wing candidates are perceived to be stronger at, for example, fighting crime and terrorism while left-wing candidates are perceived to be stronger at, say, fighting poverty and unemployment, our model predicts partisan differences in deliberate inefficiencies: At times, right-wing incumbents should fight crime and terrorism inefficiently while left-wing incumbents should sometimes be deliberately inefficient at curbing poverty and unemployment.

\section{Appendix A: Proofs}

Proof of Lemma 1: Because $c^{\prime}(y)>0, c^{\prime \prime}(y) \geq 0, y\left(q_{t}, z, A\right)<y\left(q_{t}, z, B\right)$ and $0<$ $\partial y\left(q_{t}, z, A\right) / \partial z<\partial y\left(q_{t}, z, B\right) / \partial z, \Delta u(z)$ is strictly increasing in $z$. Continuity of $c(y)$ in $y$ and of $y(q, z, i)$ in $z$ imply that $\Delta u(z)$ is continuous in $z$. Hence, there exists a unique $\tilde{z}$, and $\Delta u(z) \geq 0$ if and only if $z \geq \tilde{z}$.

Proof of the uniqueness part of Proposition 1: Since the voter always elects $A$ for $y_{1} \geq y^{H}$ and $B$ for $y_{1} \leq y^{L}$, it follows that $B$ is never reelected when playing $\underline{q}$ in states $z \geq \tilde{z}$, but always when playing $\bar{q}$ in states $z<\tilde{z}$. Consequently, there exists no $z$ such that $B$ is reelected when playing $\underline{q}$ while $A$ is elected when playing $\bar{q}$. Since playing $\bar{q}$ moreover leads to lower costs $c\left(y_{1}\right)$, there can be no equilibrium in which $B$ plays $\underline{q}$ for some $z$.

Proof of the uniqueness part of Proposition 2: We know that $A$ plays $\bar{q}$ for $z<z^{L}$ and $z \geq z^{H}$. Further, given $\Psi \leq \underline{\Psi}, A$ also plays $\bar{q}$ for any $z \in\left[z^{L}, \bar{z}^{\prime}\right)$. Given this, there can be no 
equilibrium in which $A$ plays $\underline{q}$ for $z \in\left[\bar{z}^{\prime}, z^{H}\right)$ since it would then pay for $A$ to deviate and to play $\bar{q}$, as this would still lead to his reelection by definition of $y^{\prime}$ and $\bar{z}^{\prime}$. Hence, there can be no equilibrium in which $A$ plays $\underline{q}$ for some $z$.

Proof of Proposition 3: The proof has two parts. We first prove that the strategy profile and the beliefs consistent with it constitute a PBE that satisfies our restriction on off equilibrium beliefs. Second, we show that there exists no other PBE in pure strategies that satisfies this restriction. For notational ease, we set $\mu\left(\underline{z} \mid y_{1}\right) \equiv \mu\left(\underline{z}\left(y_{1}\right) \mid y_{1}\right)$. Remember that $\mu\left(\bar{z}\left(y_{1}\right) \mid y_{1}\right)=$ $1-\mu\left(\underline{z} \mid y_{1}\right)$.

Part I (Existence): First, we show that $A$ does not want to deviate given the voter's strategy. For $z<\underline{z}^{\prime}$, the voter elects $B$ for any $q_{1}$. Hence $\bar{q}$ is $A$ 's best response. For $z \in\left[\underline{z}^{\prime}, \bar{z}^{\prime}\right)$, the voter reelects $A$ if and only if he plays $q$. Hence $q$ is $A$ 's best response given $\Psi>\bar{\Psi}$. For $z \geq \bar{z}^{\prime}$, the voter reelects $A$ for any $q_{1}$. Hence $\bar{q}$ is $A$ 's best response.

Second, we show that on equilibrium the voter's beliefs are updated according to Bayes' rule and consistent with $A$ 's strategy. Given $A$ 's strategy, observations $y_{1}<y\left(\bar{q}, \underline{z}^{\prime}, A\right)$ are only consistent with $A$ having played $\bar{q}$. Hence, $\mu\left(\underline{z} \mid y_{1}\right)=0$ for such observations. Given $A$ 's strategy and observations $y_{1} \in\left[y^{\prime}, y\left(\underline{q}, \bar{z}^{\prime}, A\right)\right), \mu\left(\underline{z} \mid y_{1}\right)=\frac{f\left(\underline{z}\left(y_{1}\right)\right)}{f\left(\bar{z}\left(y_{1}\right)\right)+f\left(\underline{z}\left(y_{1}\right)\right)}$ by Bayes' rule. Given $A$ 's strategy, observations $y_{1} \geq y\left(q, \bar{z}^{\prime}, A\right)$ are only consistent with $A$ having played $\bar{q}$. Hence, $\mu\left(\underline{z} \mid y_{1}\right)=0$ for such observations.

Third, we derive the voter's beliefs off equilibrium. Any observation $y_{1} \in\left[y\left(\bar{q}, \underline{z}^{\prime}, A\right), y^{\prime}\right)$ is consistent with $\underline{q}$ being played in state $\underline{z}\left(y_{1}\right)$ and $\bar{q}$ being played in state $\bar{z}\left(y_{1}\right)$, both of which are not played on equilibrium. Let $\varepsilon>0$ be the probability that such an "error" occurs in either state and denote by $\mu_{\varepsilon}\left(\underline{z} \mid y_{1}\right)$ the updated belief that $z=\underline{z}\left(y_{1}\right)$. Then, $\mu_{\varepsilon}\left(\underline{z} \mid y_{1}\right)=$ $\frac{\varepsilon f\left(\underline{z}\left(y_{1}\right)\right)}{\varepsilon f\left(\underline{z}\left(y_{1}\right)\right)+\varepsilon f\left(\bar{z}\left(y_{1}\right)\right)}=\frac{f\left(\underline{z}\left(y_{1}\right)\right)}{f\left(\underline{z}\left(y_{1}\right)\right)+f\left(\bar{z}\left(y_{1}\right)\right)}$.

Fourth, we show that the voter's strategy is optimal given her beliefs. Given $y_{1}<y\left(\bar{q}, \underline{z}^{\prime}, A\right)$ and beliefs $\mu\left(\underline{z} \mid y_{1}\right)=0$, electing $B$ is obviously her best response. Given $y_{1} \in\left[y\left(\bar{q}, \underline{z}^{\prime}, A\right), y^{\prime}\right)$ and beliefs $\mu\left(\underline{z} \mid y_{1}\right)=\frac{f\left(\underline{z}\left(y_{1}\right)\right)}{f\left(\bar{z}\left(y_{1}\right)\right)+f\left(\underline{z}\left(y_{1}\right)\right)}$, electing $B$ is her best response by definition of $y^{\prime}$ (and our assumption that $y^{\prime}$ is unique). Given $y_{1} \in\left[y^{\prime}, y\left(\underline{q}, \bar{z}^{\prime}, A\right)\right)$ and beliefs $\mu\left(\underline{z} \mid y_{1}\right)=\frac{f\left(\underline{z}\left(y_{1}\right)\right)}{f\left(\bar{z}\left(y_{1}\right)\right)+f\left(\underline{z}\left(y_{1}\right)\right)}$, electing $A$ is her best response by definition of $y^{\prime}$. Given $y_{1} \geq y\left(\underline{q}, \bar{z}^{\prime}, A\right)$ and beliefs $\mu\left(\underline{z} \mid y_{1}\right)=0$, electing $A$ is again her best response. This completes the proof of the existence part.

Part II (Uniqueness): The discussion in the text rules out any alternative equilibrium strategies for $z<z^{L}$ and $z \geq z^{H}$. Claims 3.1 to 3.4 below rule out all alternative candidate equilibrium 
strategies in the interval $\left[z^{L}, z^{H}\right)$.

Claim 3.1: For any pair $\left(\underline{z}\left(y_{1}\right), \bar{z}\left(y_{1}\right)\right) \in\left[z^{L}, \tilde{z}\right) \times\left[\tilde{z}, z^{H}\right)$, there is no equilibrium in which $A$ plays $\bar{q}$ at $\underline{z}\left(y_{1}\right)$ and $\bar{z}\left(y_{1}\right)$.

Proof: Suppose he would. Then, the voter's beliefs are $\mu\left(\underline{z} \mid y_{1}\right)=0$ when observing $y_{1}=$ $y\left(\bar{q}, \underline{z}\left(y_{1}\right), A\right)$ or $y_{1}=y\left(\bar{q}, \bar{z}\left(y_{1}\right), A\right)$. She thus elects $B$ if $y_{1}=y\left(\bar{q}, \underline{z}\left(y_{1}\right), A\right)$, and reelects $A$ if $y_{1}=y\left(\bar{q}, \bar{z}\left(y_{1}\right), A\right)$. Given this strategy of the voter, and since $y\left(\bar{q}, \bar{z}\left(y_{1}\right), A\right)=y\left(\underline{q}, \underline{z}\left(y_{1}\right), A\right)$ and $\Psi>\bar{\Psi}, A$ has an incentive to deviate and to play $q$ in state $\underline{z}\left(y_{1}\right)$.

Claim 3.2: For any pair $\left(\underline{z}\left(y_{1}\right), \bar{z}\left(y_{1}\right)\right) \in\left[z^{L}, \tilde{z}\right) \times\left[\tilde{z}, z^{H}\right)$, there is no equilibrium in which $A$ plays $\underline{q}$ at $\underline{z}\left(y_{1}\right)$ and $\bar{z}\left(y_{1}\right)$.

Proof: Suppose he would. Then, the voter's beliefs are $\mu\left(\underline{z} \mid y_{1}\right)=1$ when observing $y_{1}=$ $y\left(\underline{q}, \underline{z}\left(y_{1}\right), A\right)$ or $y_{1}=y\left(\underline{q}, \bar{z}\left(y_{1}\right), A\right)$. She thus elects $B$ if $y_{1}=y\left(\underline{q}, \underline{z}\left(y_{1}\right), A\right)$, and reelects $A$ if $y_{1}=y\left(\underline{q}, \bar{z}\left(y_{1}\right), A\right)$. Given this strategy of the voter, $A$ has an incentive to deviate and to play $\bar{q}$ in state $\underline{z}\left(y_{1}\right)$ because he is not reelected anyway and $c^{\prime}\left(y_{1}\right)>0$.

Claim 3.3: For any pair $\left(\underline{z}\left(y_{1}\right), \bar{z}\left(y_{1}\right)\right) \in\left[z^{L}, \underline{z}^{\prime}\right) \times\left[\tilde{z}, \bar{z}^{\prime}\right)$, there is no equilibrium in which $A$ plays $\underline{q}$ in state $\underline{z}\left(y_{1}\right)$ and $\bar{q}$ in state $\bar{z}\left(y_{1}\right)$.

Proof: By definition of $y^{\prime}$, when observing $y_{1}=y\left(\underline{q}, \underline{z}\left(y_{1}\right), A\right)=y\left(\bar{q}, \bar{z}\left(y_{1}\right), A\right)<y^{\prime}$, the voter elects $B$. Hence, in state $\underline{z}\left(y_{1}\right) A$ would have an incentive to deviate and to play $\bar{q}$, as this would improve the policy outcome without affecting the probability of reelection. Moreover, in state $\bar{z}\left(y_{1}\right) A$ would also have an incentive to deviate and to play $\underline{q}$, which would lead to $y_{1}>y^{H}$ and therefore ensure his reelection.

Claim 3.4: For any pair $\left(\underline{z}\left(y_{1}\right), \bar{z}\left(y_{1}\right)\right) \in\left[\underline{z}^{\prime}, \tilde{z}\right) \times\left[\bar{z}^{\prime}, z^{H}\right)$, there is no equilibrium in which $A$ plays $\bar{q}$ in state $\underline{z}\left(y_{1}\right)$ and $\underline{q}$ in state $\bar{z}\left(y_{1}\right)$ and which satisfies our restriction on the off equilibrium beliefs.

Proof: Suppose $A$ plays $\bar{q}$ in state $\underline{z}\left(y_{1}\right)$ and $\underline{q}$ in state $\bar{z}\left(y_{1}\right)$. Then the voter elects $B$ when observing $y_{1}=y\left(\bar{q}, \underline{z}\left(y_{1}\right), A\right)$. To prevent $A$ from deviating and playing $\underline{q}$ in state $\underline{z}\left(y_{1}\right)$, the voter must elect $B$ also when observing $y_{1}=y\left(\underline{q}, \underline{z}\left(y_{1}\right), A\right) \geq y^{\prime}$. For electing $B$ to be optimal given her beliefs, it must hold that $\mu\left(\underline{z} \mid y_{1}\right)>\frac{f\left(\underline{z}\left(y_{1}\right)\right)}{f\left(\underline{z}\left(y_{1}\right)\right)+f\left(\bar{z}\left(y_{1}\right)\right)}$ by construction of $y^{\prime}$ (and since $\left.y_{1} \geq y^{\prime}\right)$. However, as shown in part I of the proof, the only off equilibrium beliefs consistent with our restriction are $\mu\left(\underline{z} \mid y_{1}\right)=\frac{f\left(\underline{z}\left(y_{1}\right)\right)}{f\left(\underline{z}\left(y_{1}\right)\right)+f\left(\bar{z}\left(y_{1}\right)\right)}$. 


\section{References}

[1] Alesina, A., Cukierman A., 1990. The politics of ambiguity. Quarterly Journal of Economics 105, 829-850.

[2] Ansolabehere, S., Snowberg, E., Snyder, J.M., 2006. Television and the incumbency advantage in U.S. elections. Legislative Studies Quarterly 31, 469-490.

[3] Ansolabehere, S., Snyder, J.M., 2002. The incumbency advantage in U.S. elections: An analysis of state and federal offices, 1942-2000. Election Law Journal 1, 315-338.

[4] Bartels, L.M., 1996. Uninformed votes: Information effects in presidential elections. American Journal of Political Science 40, 194-230.

[5] Berrebi, C., Klor, E., 2006. On terrorism and electoral outcomes: Theory and evidence from the Israeli-Palestinian conflict. Journal of Conflict Resolution 50, 899-925.

[6] Besley, T., 2007. Principled Agents? The Political Economy of Good Government, Oxford University Press, Oxford.

[7] Beviá, C., Llavador, H., 2009. The informational value of incumbency. Journal of Public Economic Theory 11, 775-798.

[8] Blendon, R.J., Benson, J.M., Brodie, M., Morin, R., Altman, D.E., Gitterman, D., Brossard, M., James, M., 1997. Bridging the gap between the public's and economists views of the economy. Journal of Economic Perspectives 11, 105-118.

[9] Budge, I., Farlie, D., 1983. Explaining and Predicting Elections: Issue Effects and Party Strategies in Twenty-Three Democracies, G. Allen and Unwin, London, Boston.

[10] Canes-Wrone, B., Herron, M.C., Shotts, K.W., 2001. Leadership and pandering: A theory of executive policymaking. American Journal of Political Science 45, 532-550.

[11] Coate, S., Morris, S., 1995. On the form of transfers to special interests. Journal of Political Economy 103, 1210-1235.

[12] Dellis, A., 2009. The salient issue of issue salience. Journal of Public Economic Theory 11, 203-231.

[13] Dornbusch, R., Edwards, S., 1990. Macroeconomic populism. Journal of Development Economics $32,247-277$.

[14] Grossman, S., Perry, M., 1986. Perfect sequential equilibrium. Journal of Economic Theory 39, 97-119.

[15] Holmström, B., 1999. Managerial incentive problems: A dynamic perspective. Review of Economic Studies 66, 169-182.

[16] Petrocik, J., 1996. Issue ownership in presidential elections, with a 1980 case study. American Journal of Political Science 40, 825-850.

[17] Petrocik, J., Benoit, W., Hansen, G., 2003. Issue ownership and presidential campaigning, $1952-$ 2000. Political Science Quarterly 118, 599-626.

[18] Rogoff, K., Sibert, A., 1988. Elections and macroeconomic policy cycles. Review of Economic Studies 55, 1-16.

[19] Rogoff, K., 1990. Equilibrium political budget cycles. American Economic Review 80, 21-36.

[20] Shi, M., Svensson, J., 2006. Political budget cycles: Do they differ across countries and why?. Journal of Public Economics 90, 1367-1389. 
[21] Wilkinson, S., 2004. Votes and Violence: Electoral Competition and Ethnic Riots in India, Cambridge University Press, Cambridge.

[22] Wilkinson, S., 2009. Riots. Annual Review of Political Science 12, 329-343. 